\title{
Research on the Case Base of Automobile Welding Jig
}

\author{
Wang Shaoni ${ }^{1, \text { a }}$ \\ ${ }^{1}$ Shandong Polytechnic, Jinan, 250104, Shandong, China \\ azni1978@126.com
}

Keywords: Automobile Welding Jig; Case Base; Parametrical Design

\begin{abstract}
The classification of case jig is firstly studied in view of kinematics and mechanism in this paper. The parametrical design of part and their assembly of automobile welding jigs is dealt with. And then the case base of automobile welding jig is constructed, where Group Technology (GT) is applied to the coding data base of jig. Finally, the management system of automobile welding jig case base is developed.
\end{abstract}

\section{Introduction}

With the development of the automotive industry, automobile welding jig design research has become a hot spot, especially in the knowledge-based design and intelligent design (automatic design) fields. On the one hand the automobile welding jig design and production time is an important part of the automobile production cycle and it has become one of the bottlenecks for automotive production development. So this topic has a very important value for improving the efficiency of automobile welding jig design and quality. On the other hand, the body modular design, weldment shape, and structure complex features determine that automobile welding jig is modularity, flexibility, diversity and complexity. So how to make a new design using a large number of automobile welding jig parts files have become a very significant research in this field.

In the knowledge-based design studies, according to different modes of reasoning, there are two design directions: rule-based design and case-based design. The similarity of automobile body structure determines the similarity of automobile welding jig. The features of standardized and modular welding jig make case-based reasoning intelligent CAD possible [1]. In this paper, on the basis of summarizing automobile welding jig design experience and analysis of all types of automobile welding jig, automobile welding jig is encoded by using group technology and parameterization of the case based on NX. A case database management system is developed and studied [2].

\section{Construction of automobile welding jig case base}

Automotive welding jig case is a common and typical single set of jig unit; the jig unit is the morphology of positioning reference in the process of body parts welding. Currently the emphasis of automotive welding fixture design research has been focused on the parameters of the components, but it is very little to research for parameters of a single set of jig [3]. On the one hand, the structure of automobile welding jig is usually very complex, and it is difficult to parameterize cases; on the other hand, automobile welding jig case database is a huge model database, which is very difficult to research, apply and manage [4].

\section{Case database structure}

According to the structural characteristics of the existing automobile welding jig, the standardized and parametric structural model is classified as kinematics and mechanism. It can be divided into: no driven, cylinder-driven, human-driven. It is noteworthy that, motor drive and hydraulic drive jig of automobile welding jig is not included in the classification of this paper. 
Individual positioning jig is the typical representative of no driven jig; cylinder-driven jig is a pneumatic clamp powered by cylinder; human-driven is a manual clamp. Different drive mode will cause differences in the structure of the welding jig, but to a welding line, the driving mode of welding jig is the same in a station. Because individual positioning jig is special, it can be mixed with the other two types of jigs.

\section{No driven jig (Individual positioning jig)}

Individual positioning jig is a jig unit that only has the positioning element (dowel pin or locating block) and doesn't need to have the opening device. This jig includes three types: dowel pin positioning jig, locating block positioning jig and dowel pin and locating block hybrid positioning jig.

(1) The dowel positioning pin jig can be divided into two forms: one-pin positioning jig and two-pins positioning jig, which the dowel pin is the only positioning element and fixed. One-pin positioning jig is shown in Figure 1. Two-pins positioning jig is shown in Figure 2.

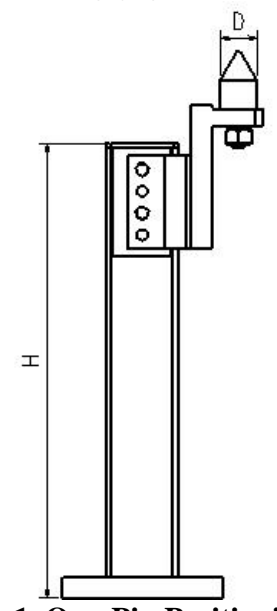

Fig. 1 One-Pin Positioning Jig

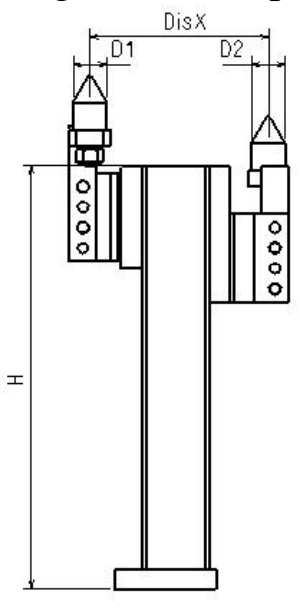

Fig. 2 Two-Pins Positioning Jig
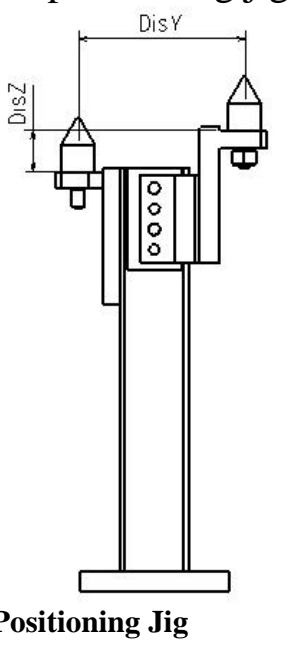

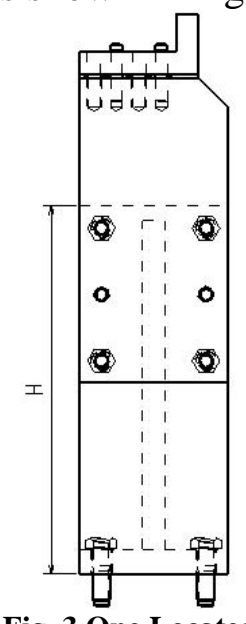

Fig. 3 One Locat Face Jig

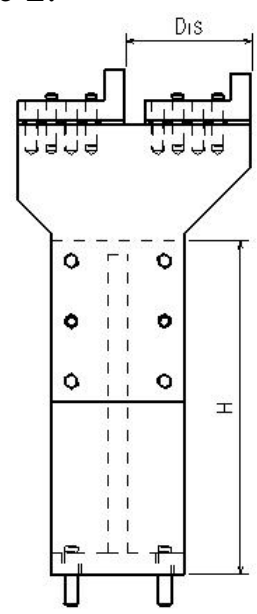

Fig.4 Two Located Faces Jig

(2) Locating block positioning jig can be divided into two forms: one located face and two located faces; its characteristics are just locating block as a positioning element. One located face jig is shown in Figure 3. Two located faces jig is shown in Figure 4.

(3) The dowel pin and locating block hybrid positioning jig is one type of individual positioning jig that its positioning element is a combination of the above two types.

\section{Pneumatic jig and manual jig}

Shown in Fig.5, the manual jig means its clamping mechanism clamp the work piece by manual operating, the clamp is generally used for the four-bar self-locking mechanism. Pneumatic jig push clamping mechanism for clamping the work piece through the cylinder using compressed air. The structural classification of pneumatic jig and manual jig is similar: one-direction open jig means the opening device of jig unit open in one direction (clockwise or counterclockwise), in order to take place body weldments; two-directions open jig means the rotating arm of jig unit open in both directions. This type of the jig unit comprises at least two dynamic driving devices.

(1) One-direction open jig

Either manual jig or pneumatic jig, the one-direction open jig includes two structural forms: Once-Swing Structure and Twice-Swing Structure. As shown in Fig.6, once-swing jig means it can take place

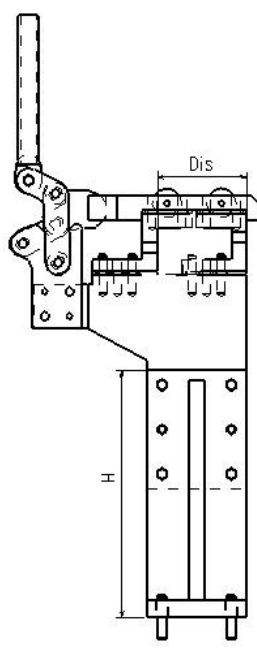

Fig. 5 Once-Swing Manual Jig the body weldment with opening one device; but some jigs can't be opened with once-swing for complex body, so the structure of jig is usually twice-swing so that there are two rotating devices in the same rotating structure, in order to take place the body weldment easily. Twice-Swing Manual Jig is shown in Fig.7. 
The Once-Swing structure of pneumatic jig can be divided into one-link swing structure and two-link swing structure. The one-link swing structure is a kind of crank shaper mechanism; it is the simplest and most common jig structure. The two-link swing structure is a kind of slider-crank mechanism. Two-Link Jig is shown in Fig.8.

(2) Two-direction open jig

Two-direction open jig means the rotating devices should be opened in both directions in a rotating plane in order to take place the body weldment. This structure is often used for the stamping with deep flange on both sides and needed for clamping welding, such as the end of back longitudinal beam. Two-direction open jig is shown in Fig.7.

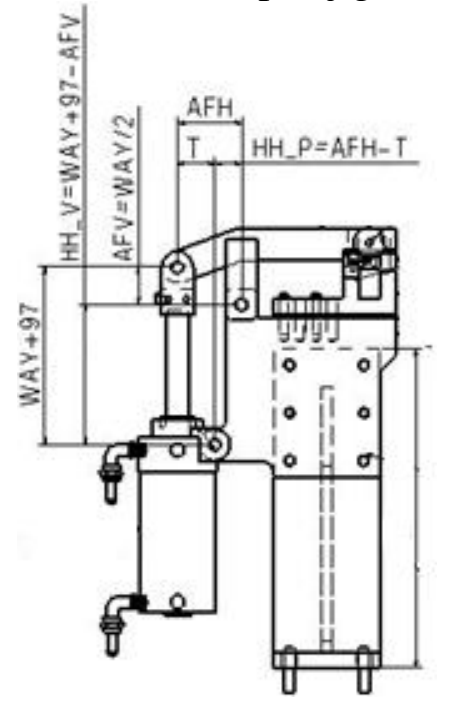

Fig. 6 Once-Swing Pneumatic Jig

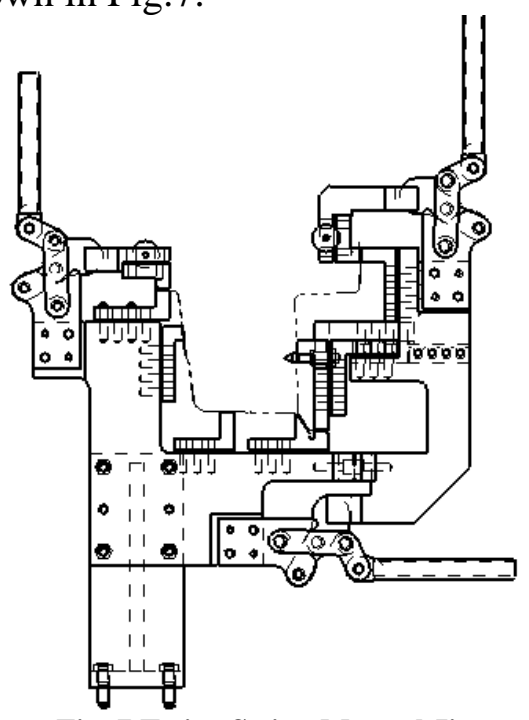

Fig. 7 Twice-Swing Manual Jig

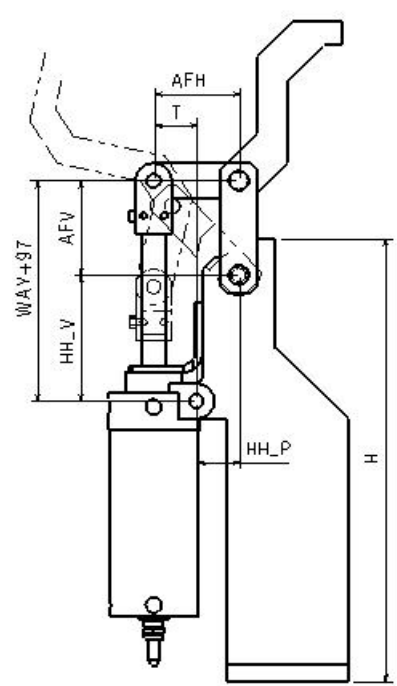

Fig. 8 Two-Link Jig

\section{Complex jig}

Complex jig includes some complex and irregular jig units. If the designer does not still find a suitable case after searching basic fixture types, he could search this case base and select the appropriate structural units from it.

Considering the above classification methods, the structure of automobile welding jig case base is shown in Fig.9.

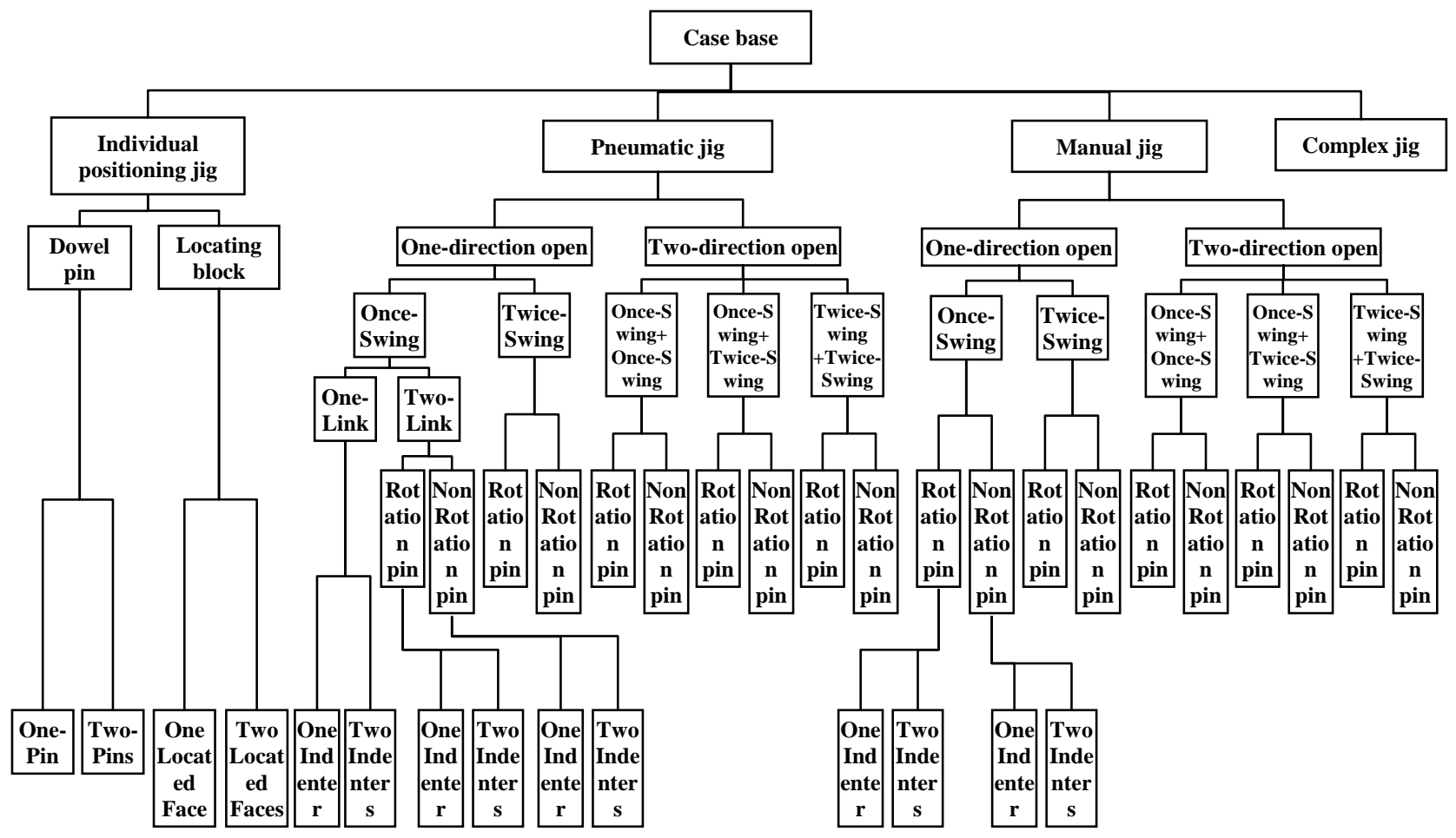

Fig. 9 Structure of Automobile Welding Jig Case Base 


\section{Case parameterization}

Parametric design is also named as dimension driving, which uses a set of parameters to define the geometry dimensions and constrain dimensional relationship, in order to offer the designer geometric modeling. Parametric design can greatly improve the speed of design and modification. According to the structure of the case base, extracting the structure characteristic parameters of jig unit, the parameterized lists are shown. Several typical structural parameters are shown in Table 1, the data in Table 1 is the parameters of once-swing pneumatic jig shown as Fig.6. The parameters of jig unit are divided into attribute parameters and size parameter. Attribute parameters are included: Drive types, Open mode, Rotation times, Number of rotational dowel pin, Number of mobile dowel pin, Number of fixed dowel pin, Number of located face, Number of clamped face and so on; Size parameter included: Jig thickness, Jig height, Dowel pin diameter, Vertical arm, Horizontal arm, Cylinder displacement and so on.

\begin{tabular}{|c|c|c|c|c|}
\hline \multicolumn{2}{|r|}{ Code } & CB110001-001-00 & CB211102-001-00 & CB311012-001-00 \\
\hline \multirow{8}{*}{$\begin{array}{l}\text { Attribute } \\
\text { parameters }\end{array}$} & Drive types & 1 & 2 & 3 \\
\hline & Open mode & 0 & 1 & 2 \\
\hline & Rotation times & 0 & 1 & 2 \\
\hline & Number of rotational dowel pin & 0 & 0 & 0 \\
\hline & Number of mobile dowel pin & 0 & 0 & 0 \\
\hline & Number of fixed dowel pin & 1 & 0 & 0 \\
\hline & Number of located face & 0 & 2 & 2 \\
\hline & Number of clamped face & 0 & 2 & 2 \\
\hline \multirow{8}{*}{ Size parameter } & Jig thickness & 16 & 16 & 16 \\
\hline & Jig height & 250 & 300 & 300 \\
\hline & Dowel pin diameter & 7.8 & 0 & 0 \\
\hline & Vertical arm & 0 & 35 & 0 \\
\hline & Horizontal arm & 0 & 35 & 0 \\
\hline & Cylinder displacement & 0 & 70 & 0 \\
\hline & HH_V & 0 & 1 & 0 \\
\hline & HH_P & 0 & 1 & 0 \\
\hline
\end{tabular}

\section{Summary}

This paper parameterizes the case and constructs automobile welding jig case base based on the analysis of automobile welding jig. Case base provides a data base for intelligent design of automobile welding jig..

\section{References}

[1] Zhang Junhua and Ying Hua: The establishment of the three-dimension enterprise standard part database based unigraphics. Modern Manufacturing Engineering Vol. 37-39 (2003), p.5

[2] Sheng Buyun, Ding Yufeng and Yang Mingzhong: Auto cover welding jig design method in virtual manufacturing system. Journal of Wuhan University of Technology Vol. 21-25 (1998), p.20

[3] Zhang Junhua and Jiang Haode: Application of second development technology based on unigraphics in establishment of enterprise standard part database. Journal of Yantai University Vol.146-151 (2004), p.17

[4] Xu Qinliang and Zhang Junhua: The study of case-based design of welding jig. Machinery Design \& Manufacture Vol.188-190, (2007), p8 